\title{
Tendências e tensões no trabalho docente: reflexões a partir da voz dos professores
}

\section{Maria Assunçáo Flores*}

\section{Resumo}

Neste artigo apresentamos um conjunto de reflexôes sobre o trabalho docente a partir das vozes dos professores que participaram num estudo mais vasto em Portugal. Partindo de testemunhos de vários docentes e convocando a literatura existente neste domínio, analisamos um conjunto de dimensóes e de tendências do trabalho docente, nomeadamente, a crescente burocracia, a intensificação e o controle sobre o trabalho dos professores; a agenda da prestaçâo de contas e da performatividade e a cada vez maior vigilância e escrutínio público em relaçáo ao trabalho das escolas e dos professores. Este texto baseia-se em dados de uma investigaçáo em curso que procura analisar os efeitos das recentes medidas políticas, nomeadamente relativas à avaliação do desempenho e ao estatuto da carreira docente, no trabalho dos professores a partir de dados recolhidos em duas escolas portuguesas. $\mathrm{O}$ texto termina com algumas reflexôes sobre os efeitos das recentes tendências no modo de estar e de viver a profissão docente, especialmente no que se refere à motivação para permanecer ou abandonar o ensino e à sua dimensão afectiva e emocional.

Palavras-chave: Trabalho docente. Profissionalismo. Identidade profissional.

* Doutora em Educação pela Universidade de Nottingham (UK). Professora Auxiliar com Agregação. Universidade do Minho, Portugal. 


\section{Introdução}

Como professora tenho de fazer muitas coisas, preencher papelada e outras tarefas administrativas e isto impedenos de ajudar os alunos e de os apoiar. Passamos muito tempo a preencher papéis e documentos em vez de nos centrarmos no ensino. Acho que as reformas têm afectado o nosso principal papel como professores. (Professora, 15 anos de experiência, Portugal)

Este excerto de uma das professoras que participaram num estudo recente sobre Avaliação do Desempenho e Desenvolvimento Profissional (realizado em Portugal) ilustra bem uma das dimensóes centrais que caracteriza o trabalho docente: a crescente burocracia e os seus efeitos no modo de estar e de viver a profissão, descentrando o docente do seu trabalho pedagógico com os alunos, com implicaçóes ao nível do profissionalismo docente e das identidade(s) profissional(ais) dos professores.

$\mathrm{O}$ ensino tem sido descrito como uma actividade cada vez mais exigente. A incerteza, a imprevisibilidade, a complexidade e a multiplicidade de tarefas associadas à docência têm sido apontadas como característicaschave de uma profissão em mudança que tem de ser entendida à luz de um determinado contexto social, político, cultural e económico.

Ao longo das duas últimas décadas, as escolas, e consequentemente os professores, têm sido confrontados com novos desafios, nomeadamente o alargamento das suas responsabilidades e dos seus papéis (em virtude, por exemplo, dos contextos multiculturais em que têm de trabalhar, das alteraçóes ocorridas na estrutura familiar e da expansão das suas funçóes que ultrapassam o âmbito da sala de aula e da disciplina), a crescente influência dos media na educação dos alunos, a coexistência de diferentes modelos educacionais numa sociedade multicultural, o aumento de oportunidades para aprender fora da escola devido ao desenvolvimento das tecnologias da informação e comunicaçáo, a crescente burocracia, prestação de contas e escrutínio público, entre outros (DAY, 1999; ESTEVE, 2000; ESTRELA, 2001; HARGREAVES, 2001).

Como lembra Hadji (2010), falando da realidade francesa, mas que é também aplicável a outros contextos, registou-se, nos últimos anos, uma mudança das expectativas em relação à Escola. $\mathrm{O}$ autor chama a atenção 
para a sua natureza paradoxal, uma vez que as atitudes sociais relativamente a ela são marcadas por uma forte ambivalência:

Num clima de crise económica e social, é provável que esperemos ainda mais dela. Encarregamo-la de prevenir e de regular todos os problemas: de violência social, de competência técnica e económica dos trabalhadores, de conflitos entre culturas e religióes; e, ao mesmo tempo, manifestamos a seu respeito, para o bem e para o mal, no melhor dos casos, desencanto e, no pior, desprezo. (HADJI, 2010, p. 116-117).

Hadji (2010, p. 117) refere ainda a alteração dos comportamentos escolares, "num contexto de dessacralização e de desvalorização da escola", e a mudança correlativa nas condiçóes de exercício da profissão docente, em que o paradoxo, mais uma vez, se manifesta:

os programas e métodos concebidos para um público de elite e que funcionavam muito bem com o público de outrora, escolarmente seleccionado e socialmente favorecido, aplicam-se agora a um público novo, mais diversificado, mais heterogéneo, menos 'escolar' (no sentido em que adere menos espontaneamente à ideologia da positividade imediata do trabalho escolar). (HADJI, 2010, p. 117)

o que implica que "antes de transmitir um saber, e mesmo para poder fazêlo, o professor deve, tanto mais se os seus alunos forem 'difíceis' (novos públicos), saber criar o quadro relacional, sem o qual não haverá transmissão (por parte do professor) nem aprendizagem (por parte dos alunos)".

É nesta realidade complexa e paradoxal que os professores exercem a sua profissão. A este respeito, alguns autores chamam a atenção para as expectativas elevadas e "irrealistas" e para a "hiper-responsabilização" e pressão social exercidas sobre os professores, tornando-se, muitas vezes, no "bode expiatório" do sistema educativo (GIMENO, 1991; ESTEVE, 2000; ESTRELA, 2001). Se, por um lado, são culpados do que corre mal no sistema educativo, por outro, são vistos como os detentores da chave do sucesso da educação. Contudo, e ironicamente, os professores têm sido, na maior parte das vezes, esquecidos quando de trata da sua participação 
na construção de iniciativas de mudança e de melhoria do ensino e da aprendizagem nas escolas, ainda que o seu envolvimento seja reconhecido, ao nível retórico, como uma variável chave para o sucesso das reformas educativas. Como bem notou Andy Hargreaves (2003, p. 2):

A profissão que é, muitas vezes, descrita com uma importância vital para a economia do conhecimento é a mesma que muitos grupos têm desvalorizado, que cada vez maior número de pessoas quer deixar, em que cada vez menos pessoas querem entrar, e muito poucos têm interesse em liderar. Isto é muito mais do que um paradoxo. É uma crise de proporçóes preocupantes.

O trabalho e a vida dos professores têm sido afectados de várias formas em diferentes contextos geográficos. Em muitos países, o trabalho dos professores tem sido marcado mais por rupturas do que por continuidades (CARLGREN, 1999). A preocupação em elevar os padróes de ensino e em melhorar a qualidade das aprendizagens dos alunos tem levado os governos a introduzir reformas nas escolas e no trabalho dos professores no sentido de uma maior prestação de contas, entre as quais se destaca, por exemplo, a avaliação dos professores (MIDDLEWOOD; CARDNO, 2001; AVALOS, 2004; AVALOS; ASSAÉL, 2006; ASSAÉL; PAVEZ, 2008). A forma como se encara o ensino e os professores (e como eles vêem a sua profissão e se vêem a si próprios enquanto professores) implica, portanto, uma determinada visão do profissionalismo docente que tem sido, nos últimos tempos, marcado por posiçóes distintas e, às vezes, conflituais:

[...] as alteraçóes na prática operacional do "profissionalismo" reflectem as crescentes complexidades e contradiçóes inerentes ao trabalho dos professores num mundo pós-moderno [...] o seu trabalho encerra ao mesmo tempo um desafio e uma ameaça. Tanto podem ser autónomos, como responsáveis perante outros, independentes como colaboradores, controlar o seu trabalho e não o controlar, centrados no professor como centrados no aluno. (DAY, 1999, p. 12). 
Por outras palavras, os professores podem responder de diferentes modos às mudanças "impostas", desde a aceitação (passiva) até ao pro-activismo, coexistindo, portanto, diferentes visóes do profissionalismo docente, ou, nas palavras de Whitty (2000), "diferentes tipos de profissionalismo". Mas o que significa ser professor no século XXI? Que dimensóes do trabalho docente ou do profissionalismo docente estão a ser promovidas? E que dimensóes estão a ser ameaçadas? Quais são as tendências e as tensóes na vida e no trabalho dos professores em resultado das medidas políticas e dos desafios que se colocam hoje ao ensino? Como vivem os professores estas mudanças? De que modo estas mudanças têm afectado o seu trabalho e a sua vida profissional? É sobre este conjunto de questóes que nos propomos reflectir neste texto a partir das vozes dos professores que participaram num estudo realizado em Portugal, ${ }^{1}$ convocando ainda a literatura existente neste domínio. ${ }^{2}$ Não se pretende dar conta de todos os aspectos conceptuais e metodológicos do estudo, mas tãosó, a partir de alguns testemunhos de professores portugueses, reflectir sobre o modo como estes têm vivido a profissão docente em resultado das reformas educativas mais recentes.

\section{A burocracia, o gerencialismo e o crescente controlo do trabalho dos professores}

Penso que o ensino se tornou uma profissão cada vez mais complexa. No passado era vista como a de um médico em termos de estatuto social e a verdade é que, como professores, temos de lidar com diferentes tipos de alunos vindos de diferentes backgrounds e com experiências diferentes $e$ isto torna a vida muito mais complicada. E ainda por cima o ensino está cada vez mais burocratizado e envolve cada vez mais tarefas administrativas. (Professor, 15 anos de experiência, Portugal).

Vamos para casa no final do dia e ainda temos de corrigir trabalho, planificar, pensar nas actividades e problemas dos alunos. Depois temos reunióes e planificação... Neste momento, é muito difícil ser professor, mesmo em termos familiares, passamos a maior parte do tempo na escola [...] (Professora, 16 anos de experiência, Portugal). 
Como sustentam estes testemunhos, nos últimos anos, o trabalho dos professores tornou-se mais intenso e complexo. A intensificação tem sido associada às mudanças sociais, ao volume de reformas e ao aumento das tarefas burocráticas e administrativas (SUGRUE, 2006; BALLET; KELCHTERMANS; LOUGHRAN, 2006; FLORES; DAY; VIANA, 2007), que se traduz, muitas vezes, na experiência dos professores em fazer mais do que uma coisa ao mesmo tempo e em estar sempre a pensar no seu trabalho (BRANTE, 2009). Sugrue (2004, p. 85) destaca que:

apesar da retórica da devolução da responsabilidade e da tomada de decisão, a recentralização, a crescente homogeneização e prescrição em relação ao que conta como resultados educativos "de sucesso" estão a conduzir à erosão da autonomia do professor e a minar ou diminuir os compromissos e trajectórias das suas carreiras.

O seguinte testemunho ilustra bem esta ideia:

As medidas politicas têm sido negativas devido ao aumento da burocracia. Como professores temos de preencher muitos papéis e o tempo que se dedica a estas tarefas é tempo perdido. Poderíamos usar este tempo a fazer investigação ou a investir no ensino. Hoje em dia, isso náo épossivel. (Professora, 19 anos de experiência, Portugal).

No contexto de um sistema altamente centralizado e burocrático, as expressões reiteradas nos discursos políticos sobre flexibilização, modernização, participação, autonomia (uma autonomia imposta) coexistem com uma visão normativa e prescritiva visível no volume de regras e normas emanadas centralmente de acordo com as quais as escolas e os professores têm de trabalhar, pelo que a retórica da autonomia não tem correspondência na realidade que continua limitada e controlada através de um processo de recentralização (PACHECO, 1998). A crescente ênfase nos aspectos formais, nas reunióes, nos relatórios ficou bem visível nalguns depoimentos dos professores que remetem para a intensificação do trabalho docente, quando afirmam: 
Nós chegamos ao fim do trabalho, vamos para casa, temos testes e fichas, temos de pensar em aulas, em actividades, nos problemas dos alunos, nos nossos problemas, nas reuniōes, depois as faltas, mais reuniöes e planos para fazer. [...] Nestes dois últimos anos, as coisas agravaramse um bocadito mais, a nivel do tempo que se passa na escola, não tem nada a ver... muitas vezes ocupam-nos muito tempo. (Professora, 19 anos de experiência, Portugal).

Eu costumo dizer que sou professora porque quero ser professora, no dia em que deixar de querer ser professora se calhar dedico-me a fazer outra coisa. Mas eu sou professora porque gosto, e não me vejo a vergar a determinadas tentativas, por exemplo passar alunos que não sabem. As ideias vêm de cima para baixo, não vão de baixo para cima, mesmo sendo boas ideias não sinto que elas cheguem lá cima e que surtam algum efeito. [...] Eu acho que eles não têm bem a ideia do que é a escola, como é a escola hoje, não têm a menor ideia de como ela funciona, das necessidades que a gente tem no dia-a-dia, daquilo que nós temos que ouvir todos os dias, com os encarregados de educaçáo, com os alunos etc. Eu sinto que não têm qualquer ideia disso e depois mandam normas e coisas em cima de joelho para nós fazermos, hoje vem uma série de decretos, amanhã já vem outro e depois já vem outro a contradizer aquele que, entretanto, foi feito. (Professora, 15 anos de experiência).

Em Portugal, a centralização do processo de tomada de decisão e a burocracia constituem dois elementos caracterizadores do sistema educativo que prevalecem nas estruturas e nas culturas do próprio sistema e nas escolas (LIMA, 2006; FERREIRA, 2007). Investigaçóes recentes (FLORES, 2003, 2005; MORGADO, 2003) têm demonstrado, por exemplo, a ambiguidade e ambivalência que caracterizam a visão dos professores face à autonomia curricular que eles vêem como um processo construído localmente (e não imposto), mas, ao mesmo tempo, a sua prática é marcada por rituais e rotinas associadas a mecanismos de controlo, tais como os exames nacionais e o currículo nacional, formulado em termos de competências, por exemplo. 
De um modo geral, o profissionalismo docente aparece marcado pela ambivalência e pelo conflito. A este respeito vale a pena referir alguns resultados de um estudo (FLORES; DAY; VIANA, 2007) que pretendeu analisar e compreender a(s) forma(s) como os professores (portugueses e ingleses) entendiam as mudanças mais recentes ocorridas no ensino, bem como os seus efeitos no modo como encaravam o profissionalismo docente e a(s) sua(s) identidade(s) profissional(ais). Quando questionados sobre quais as dimensóes do seu profissionalismo que estavam a ser ameaçadas, a maioria dos participantes no estudo referiu o exercício do seu juízo discricionário, os propósitos morais e sociais, o comprometimento/dedicação e o cuidado e atenção/preocupação, salientando ainda que as culturas colaborativas, a aprendizagem contínua e a complexidade das tarefas constituíam aspectos que, na sua opinião, estavam a ser promovidos. Dos discursos dos professores que participaram neste estudo emergiu um conjunto de constrangimentos no desenvolvimento do seu trabalho (FLORES; VIANA, 2004), destacando-se, entre outros, os seguintes: 1) a ausência de uma visão clara em termos de quadro político e legal, o que conduz a atitudes ambíguas e paradoxais; 2 ) a falta de (in)formação, de comunicação e de recursos para as escolas e para os professores; 3) a cultura profissional marcada pelo isolamento (alguns professores falam de uma "cultura da solidáo"); 4) a burocracia, mobilidade docente e a falta de motivação; 5) a ausência de entendimento e apropriação da mudança e dos seus conceitos-chave, o que leva à co-existência de dois tipos de discurso, um - retórico - que tende a colar-se às expectativas, exigências e linguagem das políticas curriculares, outro - a um nível prático - que remete para a ausência de mudança. Destes resultados ressalta uma concepção de profissionalismo marcada pela ambivalência, pelo conflito e pela ausência de referentes claros.

No entanto, a par destes constrangimentos, foram também identificados alguns aspectos positivos, nomeadamente: 1) o reconhecimento de algumas características do profissionalismo docente (culturas colaborativas e aprendizagem contínua que os professores tendem a valorizar); 2) uma perspectiva ecológica do ensino e da aprendizagem; 3) um entendimento mais amplo dos papéis/funçóes dos professores e das escolas; 4) um entendimento da escola enquanto contexto organizacional que envolve (ou pode envolver) os seus intervenientes num fim comum (com propósitos e objectivos partilhados); 5) uma maior consciencialização do papel 
do professor enquanto agente de mudança e 6) o reconhecimento da importância da avaliaçáo enquanto factor de motivaçáo e de valorização do profissionalismo docente (FLORES; VIANA, 2004).

Em Inglaterra, os professores também têm testemunhado um vasto conjunto de intensas reformas prolongadas no tempo (DAY; SMETHEM, 2009). É, aliás, um exemplo paradigmático a este respeito. A introdução do currículo nacional (e das suas versóes revistas), a mercantilizaçáo da educação, o crescente gerencialismo e prestação pública de contas (através de inspecçōes formais, rankings, formulação de objectivos e de metas a atingir, gestão do desempenho, exames nacionais, entre outros) estáo entre os elementos mais ilustrativos das medidas educativas naquele país. Helsby (2000), por exemplo, identificou alguns dos constrangimentos que afectam o ensino naquele contexto, tais como a intensificação do trabalho dos professores, a redução dos recursos atribuídos à educação, a crescente insularidade entre os professores, a ênfase nos testes e exames nacionais e o crescente gerencialismo nas escolas. Todos estes aspectos conduziram à erosão da autonomia dos professores e afectaram as suas identidades individuais e colectivas (DAY; SMETHEM, 2009) representando "anos de sobrevivência em vez de desenvolvimento" (DAY, 1997, p. 44).

A este propósito, Sachs (2003) propôe a distinção entre o profissionalismo gerencialista e o profissionalismo democrático. $\mathrm{O}$ primeiro surge relacionado com a mudança organizacional, com imperativos ligados a uma maior prestação de contas e com questôes de eficiência e de eficácia. De um modo geral, existem duas características que marcam este tipo de profissionalismo: a gestão eficiente resolve qualquer problema e as práticas usadas no sector privado podem ser aplicáveis ao sector público, o que aparece associado aos valores universais do gerencialismo (nomeadamente a consideração de que a gestão é intrinsecamente boa e de que os gestores devem ter margem de autonomia para gerir e os outros grupos devem aceitar a sua autoridade). Estas questóes podem ser vistas na burocracia no ensino e em algumas práticas de gestão nas escolas, muitas vezes, associadas a medidas políticas que advogam a descentralização e que levam à emergência deste discurso gerencialista (através, por exemplo, da prestaçáo de contas, de resultados mensuráveis, de rankings etc.). Neste contexto, o profissional responde a metas pré-especificadas externamente, gere bem um conjunto de alunos e documenta os seus resultados para efeitos de prestação pública 
de contas. Assim, o bom profissional é aquele que responde aos critérios de sucesso preconizados, ou seja, o que trabalha de forma eficaz e eficiente para ir ao encontro dos critérios estandardizados definidos para os alunos, para os professores e para as escolas. Contrariamente, o profissionalismo democrático procura desmistificar o trabalho profissional e construir alianças entre professores e outros agentes, enfatizando a acção colaborativa e cooperativa. O professor surge com responsabilidades mais amplas, para além da sala de aula, incluindo o contributo para a escola, para o sistema educativo, para a comunidade e para os alunos, bem como responsabilidades colectivas enquanto profissão, com vista à construção de uma sociedade mais justa e democrática (através, por exemplo, da investigação, da inovação etc.). ${ }^{3}$

Numa investigação conduzida em Portugal e em Inglaterra, Flores, Day e Viana (2007) identificaram as preocupaçóes dos professores em relação ao tempo dedicado a tarefas administrativas e burocráticas e ao modo como respondiam a novas medidas/iniciativas políticas. Os discursos dos professores apontam para níveis de pressão subjacentes às reformas nos dois países e os professores, quer os ingleses, quer os portugueses, expressaram um aumento do volume do trabalho e da burocracia e um maior controlo sobre o seu trabalho, afirmando também que normalmente trabalham para além do exigido. Estes dados corroboram outros estudos empíricos que sugerem que, através de uma agenda instrumentalista, a crescente ênfase na medição de resultados escolares através de testes ou exames nacionais, a publicação de rankings e a crescente monitorização, inspecção e metas a atingir, associados ao aumento do volume de trabalho e ao stress, estâo a diminuir os propósitos morais e sociais mais amplos dos professores (DAY; FLORES; VIANA, 2007), como, aliás, ficou também patente no relato de alguns professores, de que é exemplo o seguinte:

O sistema em si já há vários anos que vem penalizando os alunos pela burocracia que obrigam a fazer aos professores, cada vez mais nós temos mais papelada para fazer, o tempo que nós gastamos a fazer estes documentos era o tempo em que investigávamos, investíamos em preparação de coisas para os miúdos. Hoje, não é possivel porque nós somos humanos, limitados e o tempo também é limitado, e quase todos nós temos familia... (Professora, 15 anos de experiência, Portugal). 


\section{A prestação de contas e a agenda da performatividade}

De um modo geral, os analistas e os investigadores neste domínio identificam a existência de um maior controlo sobre o trabalho dos professores e o desempenho das escolas (BALL, 2003) através de mecanismos de prestação de contas que levam a uma maior pressão para aumentar os padróes de ensino e de aprendizagem e os resultados escolares dos alunos (OSBORN, 2006; DAY; SMETHEM, 2009) numa cultura marcada pelo gerencialismo e performatividade (OZGA, 2000) e pela estandardização e hiper-regulaçáo do ensino e do trabalho dos professores (HARGREAVES, 2003). Termos como padróes, melhoria, qualidade, resultados, eficácia e eficiência etc. tornaram-se elementos recorrentes na linguagem no campo educativo a par da ideia da necessidade de uma maior transparência e visibilidade do trabalho das escolas e dos professores através da prestação de contas e maior escrutínio público do seu desempenho.

As agendas das reformas educativas introduziram novas formas de controlo e de prestaçáo de contas nas escolas no sentido de regular e de monitorar o seu trabalho. Os discursos e as exigências da prestação de contas e, consequentemente, da performatividade, dominam o sector educativo no sentido de tornar mais transparente e visível o trabalho das escolas e dos docentes. Como sublinha Kelchtermans (2009, p. 63), "as escolas têm de ter um bom desempenho, têm de demonstrar a sua eficácia e de provar que o dinheiro nelas investido é usado de forma eficiente conduzindo a resultados apropriados".

Deste modo, o crescente gerencialismo e performatividade que caracterizam as directivas políticas, com uma ênfase crescente na qualidade e nos resultados, na eficácia e na eficiência, têm levado a uma visáo de educação como "mercadoria no mercado cada vez mais internacional" (KELCHTERMANS, 2009, p. 64) à luz da qual o trabalho dos professores é julgado muitas vezes com base numa perspectiva restritiva instrumental e baseada em resultados em função de padrōes (nacionais, nos países onde eles existem). Ball (2003, p. 216) descreve a perfomatividade como:

uma tecnologia, uma cultura e um modo de regulação que emprega juízos, comparaçóes e descriçôes como meios de incentivo, de controlo e de mudança - com base em recompensas e sançôes (quer materiais, quer 
simbólicas). Os desempenhos (dos indivíduos e das organizaçóes) servem como medidas de produtividade ou produto ou demonstraçóes de qualidade ou momentos de promoção ou inspecção.

Este tipo de cultura pode ser vista, por exemplo, nos testes baseados em padróes, em procedimentos de auditorias e métodos de auto-avaliação, inspecçóes de escolas, rankings etc. (FLORES; DAY; VIANA, 2007; DAY; SMETHEM, 2009; KELCHTERMANS, 2009). Neste contexto, Ball (2003, p. 215) chama a atenção para os "terrores da performatividade" e assevera que eles mudam o que os professores fazem, mas fundamentalmente "mudam quem eles são", isto é, a sua natureza e identidade. Esta "obsessão com a eficiência e a eficácia, com padróes e testes, com procedimentos de prestação de contas e rankings de escolas comparando a sua 'qualidade' em termos de resultados" (KELCHTERMANS, 2004, p. 224) conduz à mercantilização e à comodificação do trabalho das escolas e dos professores.

Neste contexto, Day e Sachs (2004, p. 7) discutem as características do profissionalismo gerencialista, isto é, baseado e orientado para os resultados, caracterizado por uma regulação externa, com o fim de implementar políticas, e orientado pela competitividade baseada no mercado e pelo controlo e aceitação/cumprimento de normas. Em oposição, o profissionalismo democrático baseia-se na profissão, pressupõe uma regulação profissional, complementa e vai para além das agendas de reforma, orienta-se para o desenvolvimento profissional, colegial e da profissão, caracterizando-se, por isso, pelo activismo e não pelo controlo e submissão, aceitação ou cumprimento.

Sugrue (2006), ao analisar o impacto das agendas internacionais na educação no contexto irlandês, chama a atençáo para um aumento da performatividade e da prestação de contas exigidas aos professores e sublinha o seu impacto negativo no que se refere à marginalização de dimensões importantes do processo educativo, nomeadamente a democratizaçáo da escolarização, a cidadania e a saúde da sociedade. De igual modo, Kelchtermans (2009, p. 66) adverte que a performatividade encerra uma "concepção reducionista da educação", na medida em que reduz e altera o que conta como ensino e qualidade das aprendizagens e o que significa ser professor. Isto significa "ignorar, negligenciar ou até mesmo negar aspectos importantes da realidade educativa" que constituem "fontes poderosas de 
motivação, comprometimento e satisfação profissional para os professores" (KELCHTERMANS, 2009, p. 66).

Assim, os sistemas de eficiência e prestação de contas e as crescentes formas de gerencialismo enfatizam uma visão de professor enquanto técnico ou executor que deve ser gerido em vez de um profissional que toma decisóes e usa o juízo discricionário no seu trabalho. Nesta perspectiva, os professores têm de responder e de cumprir as directivas políticas que acentuam a necessidade e a importância da formulação de objectivos, de resultados, de padrôes e de testes para regular e controlar o ensino e o seu trabalho.

As mudanças ocorridas no contexto político, em vários países (HELSBY, 1999; KLETTE, 2002; TORRES, 2006; JOHANNESSON, 2006; SUGRUE, 2006, 2010), inscrevem-se, assim, na lógica de um maior controlo e prestação de contas com implicações ao nível das identidades dos professores. Osborn (2006, p. 250-251), baseando-se em estudos comparativos que procuram analisar o impacto das mudanças políticas nacionais no trabalho dos professores em Inglaterra, França e Dinamarca, concluiu que, apesar das diferenças contextuais, "uma preocupação comum com a eficiência e a eficácia, a par da necessidade de produzir trabalhadores altamente qualificados para as economias avançadas, criou tendências semelhantes na implementação das políticas educativas na Europa.”

Subjacente a esta cultura burocrática e gerencialista está a assunção de que há a necessidade de controlar o trabalho das escolas e dos professores para implementar as agendas "instrumentalistas" dos governos no sentido de resolver os problemas da educação, o que surge acompanhado por um aumento de mecanismos de supervisão ou de vigilância e de maior escrutínio público.

\section{Maior vigilância e escrutínio público do trabalho dos professores}

Em vários países, os professores têm experimentado um intenso escrutínio público do seu desempenho. Para além dos testes baseados em padróes nacionais e da publicaçáo de rankings de escolas, outras formas de prestação de contas e a necessidade de maior transparência são também visíveis na maior atenção por parte dos meios de comunicação social e de outros agentes educativos. Como refere Ball (2003, p. 220), “[...] [domina] 
uma sensação de se estar constantemente a ser julgado através de diferentes meios, de acordo com diferentes critérios e diferentes agências."

Os professores sentem um aumento da vigilância em relação ao seu trabalho associada à perda de confiança na sua capacidade para proporcionar um bom serviço (DAY; SACHS, 2004), o que, por sua vez, se relaciona com as exigências de políticas públicas para que prestem contas do seu trabalho. A existência de mecanismos de supervisão e de vigilância leva a uma maior pressão por parte dos professores para cumprir a agenda de reforma dos governos. Os professores são controlados através da publicação de resultados e de rankings como "medida de desempenho" e através da crescente supervisão das suas actividades profissionais que são julgadas com base em critérios no quadro de um currículo nacional (DAY; SMETHEM, 2009). As crescentes formas de gerencialismo e de prestação de contas conduziram a uma focalização nos resultados e a uma ênfase na visibilidade e naquilo que alguns autores denominam de "tirania da transparência" (STRATHERN, 2000), afastando a sua atenção das actividades de ensino e de aprendizagem.

Para Fitzgerald (2010, p. 77), falando da realidade neozelandesa, a:

"tirania da transparência" tem desviado a atenção dos professores e dos líderes das escolas em relaçáo ao ensino, centrando-a nas hierarquias e nas estruturas e oferecendo evidência empírica sobre "boas práticas", algo que oferece provas palpáveis de que os objectivos organizacionais estão a ser cumpridos.

Como sustentam ainda Day e Smethem (2009, p. 143),

o trabalho dos professores é agora internacionalmente mais transparente, a sua qualidade mais monitorizada de perto e os próprios professores devem prestar cada vez mais contas pelo progresso e resultados dos seus alunos em função de agendas baseadas em resultados que se relacionam mais do que nunca com as metas dos governos.

Apesar das diferenças de contexto, muitos professores na Europa, e não só (por exemplo, na Austrália e na Nova Zelândia), experimentam uma crescente ênfase em diferentes formas de prestação de contas, de intensificação do seu trabalho e de uma cultura gerencialista nas escolas, 
associada a uma perspectiva de ensino orientada para os resultados, em muitos casos identificada através de um conjunto de padróes ou competências a ser alcançado. Contudo, o que a literatura sugere é um conjunto de tensóes, contradiçóes e complexidades no ensino que têm afectado o trabalho e a vida dos professores um pouco por todo o mundo. Por exemplo, Klette (2002, p. 267), escrevendo no contexto dos países nórdicos, discute duas tensóes na agenda de reestruturação dos governos que afectam o trabalho dos docentes: 1) "a tensão entre cultivar uma missão de ensino moral e mais ampla, por um lado, e, por outro, uma missão instrumental mais restrita de ensino"; 2) "a tensão entre o aumento da autonomia versus o crescente controlo dos professores” em que a retórica do profissional autónomo co-existe com "sistemas de mecanismos de controlo cada vez maiores e constrangimentos e exigências externas”. Day e Smethem (2009) também identificaram o aumento da pressão exercida sobre os professores em termos de rendimento escolar dos alunos e, ao mesmo tempo, a necessidade de atender ao seu bem-estar e cidadania. Podemos identificar ainda outra tensão: a ênfase na colaboração (uma colaboração imposta) e, simultaneamente, formas crescentes de gerencialismo e de prestação de contas do seu trabalho, associada aos resultados escolares num contexto muitas vezes marcado por uma cultura competitiva (quotas, avaliação etc.). Day e Sachs (2004, p. 5) também enunciam um conjunto de paradoxos acerca da natureza do ensino como profissão no contexto das reformas educativas ao longo dos últimos anos:

1) A necessidade (e a defesa) de um maior profissionalismo docente reinventando a identidade profissional dos professores e, ao mesmo tempo, a evidência que aponta para o facto de os professores estarem a ser desprofissionalizados e seu trabalho intensificado como resultado do currículo imposto externamente e de sistemas de monitorização e de avaliação e supervisão, tornando o acto educativo cada vez mais complexo;

2) Embora se reconheça que repensar a prática da sala de aula é uma tarefa extremamente exigente, são alocados cada vez menos recursos para apoiar a aprendizagem dos professores; 
3) Faz-se a exortação do ensino como actividade autónoma ao mesmo tempo que este se situa num contexto de maior vigilância e supervisão por parte dos políticos e da comunidade numa lógica de prestação de contas em regimes baseados em padróes.

\section{Como refere Sugrue (2010, p. 165),}

este imenso caos de agendas políticas concorrentes e, por vezes, divergentes, exige, por um lado, um maior profissionalismo, ao mesmo tempo que assistimos ao reverso desta medalha política, ou seja, ao surgimento de um clima de performatividade, devido aos parâmetros de recentralização que visam sobretudo a prestação de contas.

Por outras palavras, apesar de, de um modo geral, o trabalho dos professores ter sofrido alteraçóes no sentido de uma maior prestação de contas e performatividade que têm afectado o modo de estar e viver a profissão docente, existem visóes distintas, e até conflituais, em relação ao modo de olhar para o papel do professor na educação das crianças e dos jovens. Tudo isto tem afectado o seu sentido de profissionalismo e as suas identidades profissionais, como demonstram os seguintes testemunhos:

Há muito que é preciso recuperar a imagem do professor que se foi esbatendo [...] (Professor, 22 anos de experiência)

Eu acho que é uma profissão cada vez mais complexa, primeiro porque agora não estamos numa situação muito benéfica porque antigamente a profissão de professor era encarada quase como um médico [...] Depois lidamos com alunos muito diferentes, portanto, já não há aquelas classes homogéneas de alunos, há uma classe muito heterogénea, nós quando falamos, falamos para meninos que têm vivências completamente distintas e é muito complicado chegar a cada um deles. Depois acho que também a nossa profissão se tornou bastante burocrática, acho que se tirou muito do trabalho que era da secretaria, coisas que qualquer funcionário poderia fazer e nós estamos a ser retirados da sala de aula, estamos a ser retirados de dar apoio aos nossos meninos. Eu, às 
vezes, preciso de uma hora para lhes dar apoio e não tenho, e estamos a preencher papéis, passamos a vida a preencher papéis, a preencher formulários, e agora é mais um inquérito e é preciso preencher mais papeis, quando poderíamos estar a fazer outro tipo de coisas que são pedagogicamente aquilo para que é a minha formação: a função do professor. É isso que eu acho: estão a afastar a função do professor daquilo que era o objectivo principal. (Professora, 16 anos de experiência, Portugal).

Numa revisão recente sobre os efeitos das reformas centralmente iniciadas em Inglaterra, ao longo das duas últimas décadas, Day e Smethem (2009) concluíram que, apesar das suas intençóes para melhorar os padróes de ensino, de aprendizagem e de rendimento escolar dos alunos, a realidade é que "a reforma nem sempre leva à renovação". Estes autores concluem que "as respostas dos professores às reformas variam e nem sempre correspondem ao que outros fora do contexto da sala de aula podem desejar ou fazer acreditar", na medida em que "muitos docentes continuam nas escolas mantendo o seu comprometimento em relação aos que ensinam e mantêm a sua paixão pelo ensino" (DAY; SMETHEM, 2009, p. 154). E, sublinhando o papel chave dos líderes escolares, continuam dizendo que "não só essas escolas são capazes de ir ao encontro e exceder os resultados dos alunos, estabelecidos nacional e localmente, através das metas de aprendizagem, mas também são capazes de o fazer emancipando os professores através do uso do juízo discricionário" (DAY; SMETHEM, 2009, p. 151).

Por outro lado, um estudo longitudinal e amplo sobre o trabalho, a vida e a eficácia dos professores realizado em Inglaterra (DAY et al., 2007; SAMMONS et al., 2007; DAY, 2008) demonstrou que os professores em diferentes fases da sua carreira (no início, a meio e no final da sua vida profissional) mantinham o seu compromisso profissional, que surgia associado ao apoio por parte dos líderes escolares e dos colegas bem como do seu sentido de vocação. Uma visão similar é suportada por outros investigadores, por exemplo, Osborn (2006, p. 252) ao reconhecer que, apesar da crescente ênfase na prestação de contas, eficácia e performatividade inerente às políticas educativas, "os professores europeus estudados não eram vítimas passivas da mudança educacional imposta”. Eles, continua a autora, "tinham o potencial para, de forma activa e criativa, mediar as políticas de 
mudança e, em alguns casos, para as adaptar, alterar ou subverter" no sentido de um maior profissionalismo. Assim, as respostas dos professores à mudança imposta é "multifacetada e complexa" na medida em que "as exigências externamente impostas são mediadas pelas percepçóes, compreensões, motivação e capacidade dos professores, individual e colectivamente, em diferentes contextos para produzir determinadas práticas e acçóes" (OSBORN, 2006, p. 252). Contudo, a autora adverte que "existe o perigo de, a longo prazo, a "cultura da performatividade" prevalecente poder influenciar as perspectivas dos professores em relação a si próprios e silenciar vozes alternativas em relação aos objectivos da educação" (OSBORN, 2006, p. 252).

Os professores podem responder de modo diferente às iniciativas de reforma; enquanto alguns podem reagir passivamente às reformas centralmente emanadas numa cultura de conformismo e aceitação, e até de resignação, em relação às agendas de prestação de contas e de performatividade, como se tem demonstrado em estudos empíricos, outros podem resistir e envolverem-se proactivamente no seu trabalho no sentido de um maior profissionalismo. Neste caso, o contexto escolar (as suas culturas e lideranças) e os valores dos professores bem como os seus propósitos morais e sociais podem fazer a diferença e mediar os efeitos da implementação das políticas. Como sustentam Goodson e Numan (2002, p. 274), "a crise da reforma é uma crise de optimismo prescritivo", destacando que a investigação que desafia essas simplificaçóes ultrapassará as visóes populares actuais no sentido de uma contracultura focalizada na vida e no trabalho quotidianos dos professores.

\section{Abandonar a profissão ou permanecer no ensino? Da fadiga e desilusão à resiliência e ao comprometimento}

Numa análise recente dos contextos de ensino na Europa, Osborn (2006) chama a atenção para o facto de a dimensão afectiva do ensino - nomeadamente o sentido de vocação e o investimento no self - estar a ser minada pela pressão do desempenho em termos de resultados escolares, numa visão de professor enquanto técnico que deve transmitir conhecimentos e desenvolver destrezas externamente pré-definidos. Também muitos professores que participaram num estudo recente realçaram a baixa 
motivação e a perda da "alma do ensino" como consequência das recentes reformas, que, segundo eles, têm afectado o "sentido essencial" do seu trabalho e daquilo que significa ser professor:

Estamos a deixar de parte as coisas importantes na escola, que é o nosso relacionamento com os alunos [...] a indisciplina deles está a tornar-se bombástica [...] (Professora, 19 anos de experiência, Portugal).

Sentimentos de cansaço, desmotivação e desilusão emergem dos relatos dos professores, que aparecem associados às reformas "intermináveis" e às pressóes para aderirem e implementar as directrizes emanadas pela Administração Central:

Acho que as pessoas estâo cada vez mais cansadas. Antigamente, as pessoas vinham para a escola felizes, mesmo quando não tinham aulas. Não era uma imposição. Hoje é uma imposição e pensamos que é melhor ficar em casa se não tivermos aulas, porque na escola estamos sob muita pressáo e sentimo-nos cansados. (Professor, 10 anos de ensino, Portugal).

Acho que antigamente tinha muita mais vontade de fazer coisas, hoje em dia, não me sinto recompensada, sinto que trabalho muito com os meus alunos na mesma [...] Mas eu sinto-me muito cansada. Acho que trabalhamos muito intensamente, sob muita pressão... há sempre noticias a denegrir-nos cada vez mais e eu acho que isto não é muito bom, as pessoas sentem-se um bocado desmotivadas. (Professora, 16 anos de experiência, Portugal).

A falta de tempo e a intensificação do trabalho docente, associadas ao stress e à desmotivação, constituem ainda aspectos críticos que têm conduzido a um decréscimo do nível de satisfação profissional dos professores. Alguns docentes referem a importância do comprometimento e da capacidade de resiliência como elementos fundamentais para se manterem no ensino: muitos sentem-se desiludidos com as recentes reformas e com vontade de abandonar a profissão. A intensificação do seu trabalho e a burocracia, a par de mecanismos de avaliação do desempenho e da cada vez maior pressão 
relativamente aos resultados escolares, conduziu à falta de motivação e à desilusão, e até a alguma frustração:

Para ser sincero, se pudesse ia embora amanhã. Há dois anos não pensava assim. Sempre quis ser professor e sentia-me motivado e gostava de ser professor e de estar com os alunos. Mas agora sinto-me completamente desmotivado, se pudesse abandonava o ensino... (Professor, 20 anos de experiência, Portugal).

Sinceramente, se eu pudesse ir embora ia já amanhã. $E$ isto não me acontecia há dois anos atrás. Sempre quis ser professora, há pessoas que não, e isso, tive sempre motivação, sempre, gosto imenso de estar com os miúdos, acho que trabalho bastante para conseguir ter bons resultados com eles, independentemente dos resultados da avaliaçâa deles, não é isso, agora estou completamente desmotivada. (Professora, 20 anos de experiência, Portugal).

Apesar do cansaço e da desilusão, alguns professores manifestam a sua intenção de permanecer no ensino e de fazer a diferença na vida dos seus alunos, que associam ao seu sentido de vocação e comprometimento. Este facto relaciona-se não só com factores pessoais (motivação para entrar e permanecer no ensino devido sobretudo ao seu relacionamento com os alunos), mas também a aspectos associados ao contexto em que trabalham, nomeadamente à cultura escolar e às lideranças que surgem como elementos mediadores no modo como os professores encaram o seu profissionalismo, comprometimento e satisfação profissional.

Há alturas em que me sinto desmotivada. Sou-lhe honesta. Há outras que não, pelos alunos porque é assim, tenho turmas em que dá vontade de trabalhar, que aderem, que participam em tudo e mais alguma coisa, que estão sempre disponiveis para, fora de horas, fazer uma coisa, fazer outra, tenho sempre gente. Tenho outras que estão sempre a olhar para o relógio, "ainda falta muito?", acho que também depende um bocadinho do aluno. A autoridade que também nos foi tirada tem um pouco de influência [...] (Professora, 18 anos de experiência, Portugal). 
Acho que nos podemos sentir desmotivados na escola. Mas náo desistimos e continuamos a lutar... vejo-me como uma pessoa de coragem e alguém que quer continuar a lutar e a acreditar no ensino, embora seja cada vez mais dificil. (Professor, 20 anos de experiência, Portugal).

\section{Em jeito de conclusão}

O discurso da prestação de contas, o "novo vocabulário da performatividade" (BALL, 2003, p. 7) e as formas de gerencialismo dominam as iniciativas emanadas centralmente na busca de uma competitividade económica cada vez maior num mundo globalizado. De um modo geral, as directivas políticas governamentais conduziram a um maior controlo do trabalho dos professores (OSBORN, 2006) através da crescente supervisão e vigilância (DAY; SMETHEM, 2009), em resultado da crescente burocracia ligada ao aumento do volume de trabalho (FLORES; DAY; VIANA, 2007), numa visão de qualidade enquanto eficácia e eficiência na consecução dos padrões (KELCHTERMANS, 2009) em termos de resultados dos alunos e de desempenho dos professores. Estas mudanças afectaram o trabalho e a vida dos docentes de vários modos. $\mathrm{O}$ estabelecimento de metas, a prestaçáo de contas, a performatividade e o escrutínio público tiveram efeitos na motivação dos professores e no seu comprometimento e desafiaram o que significa ser professor. Os professores encontram-se sob pressão para cumprir as regras e directivas (externa e centralmente definidas) e regimes baseados em padróes no sentido de aumentar a qualidade do ensino, da aprendizagem e dos resultados escolares dos alunos, o que tem afectado o seu profissionalismo e condicionado a dimensão afectiva do ensino $\mathrm{o}^{4}$ e os seus propósitos morais, bem como o seu sentido de vocação (OBSBON, 2006; DAY, 1997; DAY; FLORES; VIANA, 2007; FLORES; DAY; VIANA, 2007).

Contudo, apesar das mudanças externamente impostas e dos efeitos negativos nas realidades do trabalho dos professores, alguns professores parecem resistir e manter o seu comprometimento e eficácia em tempos de instabilidade e pressão devido, em grande medida, ao seu sentido de vocação e às características dos contextos em que trabalham, especialmente no que concerne à cultura e liderança (ACKER, 1999; BALLET; 
KELCHTERMANS; LOUGHRAN, 2006; DAY; SMETHEM, 2009; FLORES; DAY; VIANA, 2007).

Tal como argumenta Fullan (2001, p. 115), "a mudança educacional depende do que os professores fazem e pensam". O modo como entendem os seus papéis e as suas tarefas e a natureza do próprio ensino nos contextos em que trabalham - o seu profissionalismo - é vital para o sucesso da mudança e para a melhoria da qualidade do ensino e da aprendizagem nas escolas bem como a sua compreensão sobre o que significa ser professor. Como sustentam ainda McCulloch, Helsby e Knight (2000, p. 118),

a melhoria da educação depende dos professores quererem (ou não) fazer a diferença. Depende da forma como eles se sentem (ou não) profissionais. Nem elevar os standards através da regulamentação nem profissionalizar através da prescrição resultam. Os professores têm poder no sentido em que eles têm de querer melhorar para que a melhoria aconteça.

A motivação dos professores e o seu comprometimento são variáveis chave no sucesso das reformas bem como a necessidade de ter em conta o contexto em que trabalham (GOODSON, 2001) e isto implica o reconhecimento e a valorização do papel central dos professores como agentes de mudança que podem fazer a diferença na vida dos alunos. Negligenciar esta realidade tem implicaçóes para a qualidade do ensino, da aprendizagem e dos resultados dos alunos. A participação e a agência dos professores e os seus propósitos morais assumem uma importância vital para melhorar a qualidade da educação, pois, como afirmam Goodson e Numan (2002, p. 274),

se as perspectivas dos professores não forem consideradas, é provável que uma nova crise de mudança e de reforma seja criada. Pois, se os professores náo forem totalmente considerados nas novas iniciativas, a sua centralidade no processo agirá contra a essência dessas mesmas reformas.

E, mais importante, a alma do ensino, tal como um dos professores referiu numa entrevista, e que transcrevemos no final deste texto, será afectada ou perdida: 
Há profissóes que para se estar nelas é preciso ter uma alma. O ensino é uma delas. Há qualquer coisa que não se explica muito bem o que é. É preciso estar aqui com vocação. A gente sente que é o algo mais que está para além das nossas competências que são adquiridas nas universidades ou nos cursos de formação, etc. Penso que o que este modelo [de avaliação do desempenho] conseguiu foi abafar essa alma. O aspecto mais terrivel e aquele que me dói mais é que quase todos nós não temos a mesma alegria que tínhamos, nem de perto nem de longe, em vir para a escola e dar aulas. Já não há a mesma alegria. E, pior do que isso, é a sensação de que estamos à espera de que amanhã venha algo, algum decreto, estamos sempre à espera do pior. Ora, isto afecta a nossa alma, afecta o que há de mais bonito no sistema educativo que leva um professor a sorrir para os seus alunos, a brincar com eles, a ter uma energia que náo se sabe de onde é que ela vem... isso está-se a perder. (Professor, 22 anos de experiência, Portugal).

Dito de outro modo, se queremos melhorar a qualidade do ensino e da aprendizagem nas escolas e nas salas de aula, o trabalho dos professores tem de ser considerado, reconhecido e valorizado nas iniciativas de reforma e isso implica promover e manter a paixáo pelo ensino.

\section{Notas}

1 Neste texto retomam-se algumas ideias desenvolvidas no âmbito de uma conferência proferida na Faculdade de Psicologia e de Ciências da Educação, da Universidade do Porto, Portugal, em 24 de Fevereiro de 2010. Trata-se de um trabalho realizado no âmbito da minha Licença Sabática, no ano lectivo de 2008/2009, financiado pela Fundação para a Ciência e a Tecnologia (SFRH/BSAB/815/2008). Os dados foram recolhidos em duas escolas no Norte de Portugal através de questionários $(n=150)$, entrevistas semi-estruturadas $(n=45)$ e focus group $(n=10)$ no final do primeiro ciclo de implementação do novo sistema de avaliação do desempenho. Para mais detalhes sobre este estudo, veja Flores (2011a). 
2 Para uma síntese sobre a vida e o trabalho dos professores numa perspectiva europeia, veja Flores (2011b).

3 A este propósito, Sachs (2003) identifica duas formas antagónicas de identidade profissional: a empresarial e a activista. A primeira é associada a professores eficientes, responsáveis e responsabilizáveis, que demonstram uma certa obediência aos imperativos políticos impostos a partir do exterior, demonstrando um ensino de qualidade que é avaliado mediante um conjunto externo de indicadores de competência. De um modo geral, este tipo de identidade é individualista, competitiva, controladora e reguladora, definida externamente e liderada por standards. $\mathrm{Na}$ segunda, que se baseia na crença na importância da mobilização dos professores para melhorar as condiçóes de aprendizagem dos alunos, os professores preocupam-se sobretudo em criar e desenvolver standards e processos de ensino que possam proporcionar aos alunos experiências democráticas (SACHS, 2003). Segundo a autora, a primeira é o fruto desejado pelas agendas de performatividade e gestão, enquanto a segunda parece estar orientada para a investigaçáo, para salas de aula colaborativas e para escolas onde o ensino está intimamente ligado a amplos valores e ideais da sociedade e onde os objectivos do ensino e da aprendizagem transcendem o instrumentalismo de algumas reformas educativas.

4 Para uma análise da dimensão afectiva e ética do ensino, veja Estrela (2010).

\section{REFERÊNCIAS}

ACKER, S. The realities of teachers' work: never a dull moment. London: Cassell, 1999.

ASSAÉL, J.; PAVEZ, J. La construccion e implementacion del sistema de evaluacion del desempeño docente chileno: principales tensiones y desafios. Revista Iberoamericana de Evaluacion Educativa, Madrid, v. 1, n. 2, p. 41-55, 2008.

AVALOS, B. Teacher regulatory forces and accountability policies in Chile: from public servants to accountable professionals. Research Papers in Education, London, v. 19, n. 1, p. 67-85, 2004. doi: 10.1080/0267152032000179981 
AVALOS, B.; ASSAÉL, J. Moving from resistance to agreement: the case International Journal of Educational Research of the Chilean teacher performance evaluation, v. 45, p. 254-266, 2006.

BALL, S. The teacher's soul and the terrors of performativity. Journal of Education Policy, London, v. 18, n. 2, p. 215-228, 2003.

BALLET, K.; KELCHTERMANS, G.; LOUGHRAN, J. Beyond intensification towards a scholarship of practice: analysing changes in teachers' work lives. Teachers and Teaching: theory and practice, London, v. 12, n. 2, p. 209-229, 2006.

BRANTE, G. Multitasking and synchronous work: complexities in teacher work. Teaching and Teacher Education, v. 25, n. 3, p. 430-436, 2009.

CARLGREN, I. Professionalism and teachers as designers. Journal of Curriculum Studies, London, v. 31, n. 1, p. 43-56, 1999. doi: $10.1080 / 002202799183287$.

DAY, C. Committed for life? variations in teachers' work, lives and effectiveness. Journal of educational Change, v. 8, p. 243-260, 2008.

DAY, C. Developing teachers: the challenges of lifelong learning. London: Falmer, 1999.

DAY, C. et al. Teachers matter: connecting lives, work and effectiveness. Maindenhead: Open University, 2007.

DAY, C. Teachers in the twenty-first century: time to renew the vision. In: HARGREAVES, A.; EVANS, R. (Ed.). Beyond educational reform: bringing teachers back in. Buckingham: Open University, 1997. p. 4461.

DAY, C.; FLORES, M. A.; VIANA, I. Effects of national policies on teachers' sense of professionalism: findings from an empirical study in Portugal and in England. European Journal of Teacher Education, Londres/ Inglaterra, v. 30, n. 3, p. 249-266, 2007.

DAY, C.; SACHS, J. Professionalism, performativity and empowerment: discourses in the politics, policies and purposes of continuing professional development. In: DAY, C.; SACHS, J. (Ed.). International 
handbook on the continuing professional development of teachers. Maindenhead: Open University, 2004.

DAY, C.; SMETHEM, L. The effects of reform: have teachers really lost their sense of professionalism? Journal of Educational Change, n. 10, p. 141-157, 2009.

ESTEVE, J. M. The transformation of the teachers' role at the end of the twentieth century: new challenges for the future. Educational Review, Londres/Inglaterra, v. 52, n. 2, p. 197-207, 2000.

ESTRELA, M. T. Profissão docente: dimensōes afectivas e éticas. Mangualde: Pedago, 2010.

ESTRELA, M. T. Questóes de profissionalidade e profissionalismo docente. In: TEIXEIRA, M. (Org.). Ser professor no limiar do século XXI. Porto: ISET, 2001.

FERREIRA, F. I. Transformation de l'école et paradoxes de l'autonomie au Portugal. Revue internationale d'éducation de Sèvres, Paris/França, $\mathrm{n}$. 46, p. 45-54, 2007.

FITZGERALD, T. Supervisão institucionalizada? a gestáo do desempenho nas escolas da Nova Zelândia. In: FLORES, M. A. (Ed.). A avaliação de professores numa perspectiva internacional: sentidos $\mathrm{e}$ implicaçôes. Porto: Areal, 2010. p. 65-82.

FLORES, M. A. Teacher Professionalism in Portugal and Brasil: theory and practice. In: MARKEA, G. G.; PAPANIKOS, G. T. (Ed.). Global Issues of Education. Athens, Grecia, v. 2, p. 235-242, 2003.

FLORES, M. A. Teacher's perceptions of a new policy on teacher performance appraisal in Portugal. In: INTERNATIONAL CONGRESS FOR SCHOOL EFFECTIVENESS AND IMPROVEMENT (ICSEI), 24., 2011, Limassol, Chipre.

FLORES, M. A. Teacher's views on recent curriculum changes: tensions and challenges. The Curriculum Journal, Londres/Inglaterra, v. 16, n. 3, p. 401-413, 2005.

FLORES, M. A. Teacher's work and lives: a European perspective. In: DAY, C. (Ed.). Handbook on teacher and school development. New York: Sage, 2011b. 
FLORES, M. A.; DAY, C.; VIANA, I. C. Profissionalismo docente em transição: as identidades dos professores em tempos de mudança: um estudo com professores ingleses e portugueses. In: FLORES, M. A.; VIANA, I. C. (Org.). Profissionalismo docente em transição: as identidades dos professores em tempos de mudança. Braga: CIEd, 2007.

FLORES, M. A.; VIANA, I. The impact of recent elementary school curriculum reorganisation on Teacher's attitudes and practices of teaching. In: EUROPEAN CONFERENCE ON EDUCATIONAL RESEARCH (ECER), 2004, Creta.

FULLAN, M. The new meaning of educational change. 3. ed. New York: Teachers College, 2001.

GIMENO, J. Consciência e acção sobre a prática como libertação profissional dos professores. In: NÓVOA, A. (Org.). Profissáo Professor. Porto: Porto Editora, 1991.

GOODSON, I. Social histories of educational changes. Journal of Educational Change, v. 2, n. 1, p. 45-63, 2001.

GOODSON, I.; NUMAN, U. Teacher's life worlds, agency and policy contexts. Teachers and Teaching: Theory into Practice, Estado Unidos, v. 8, n. 2/3, p. 269-277, 2002.

HADJI, C. A avaliação de professores em França: da inspecção ao acompanhamento pedagógico? In: FLORES, M. A. (Ed). A avaliação de professores numa perspectiva internacional: sentidos e implicaçóes. Porto: Areal, 2010. p. 111-140.

HARGREAVES, A. Teaching as a paradoxical profession: implications for professional development. In: XOCHELLIS, P.; PAPANAOUM, Z. (Org). Continuing teacher education and school development (Symposium Proceedings). Thessaloniki: Department of Education/ School of Philosohy AUTH, 2001. p. 26-38.

HARGREAVES, A. Teaching in the knowledge society: education in the age of insecurity. Maidenhead: Open University, 2003.

HELSBY, G. Changing teacher's work. Buckingham: Open University, 1999. 
HELSBY, G. Multiple truths and contested realities: the changing faces of teacher professionalism in England. In: DAY; C. et al. (Ed.). The life and work of teachers: international perspectives in changing times. London: Falmer, 2000.

JOHANNESSON, I. A. 'Different children - a tougher job': icelandic teachers reflect in changes in their work. European Educational Research Journal, Londres/Inglaterra, v. 5, n. 2, p.140-151, 2006.

KELCHTERMANS, G. CPD for Professional Renewal: moving beyond knowledge for practice. In DAY, C.; SACHS, J. (Ed.). International Handbook on the Continuing Professional Development of Teachers. Maidenhead: Open University, 2004.

KELCHTERMANS, G. O comprometimento profissional para além do contrato: auto-comprensão, vulnerabilidade e reflexão dos professores. In: FLORES, M. A.; VEIGA SIMÃO, A. M. (Ed.). Aprendizagem e desenvolvimento profissional de professores: contextos e perspectivas. Mangualde: Pedago, 2009.

KLETTE, K. Reform policy and teacher professionalism in four nordic countries. Journal of Educational Change, v. 3, n. 3/4, p. 265-282, 2002.

KLETTE, K. Working-time blues: how norwegian teachers experience restructuring in education. In: DAY, C. et al. (Ed.). The life and work of teachers. international perspectives in changing times. London: Falmer, 2000.

LIMA, L. Administração da educação e autonomia das escolas. In:

LIMA, L. et al. A Educação em Portugal (1986-2006): alguns contributos de investigação. Portugal: Sociedade Portuguesa de Ciências da Educação, 2006. p. 5-54.

MCCULLOCH, G.; HELSBY, G.; KNIGHT, P. The politics of professionalism: teachers and the curriculum. London: Continuum, 2000.

MIDDDLEWOOD, D.; CARDNO, C. Managing teacher appraisal and performance: a comparative approach. London: RoutledgeFalmer, 2001.

MORGADO, J. C. Processos e práticas de (re)construção da autonomia curricular. 2003. Tese (Doutorado em Educação, especialidade de Desenvolvimento Curricular)-Universidade do Minho, Braga, 2003.

OSBORN, M. Changing the context of teacher's work and professional 
development: a European perspective. International Journal of Educational Research, Londres/Inglaterra, v. 45, p. 242-253, 2006.

OZGA, J. Education: new labour, new teachers. In: CLARK, J.; GEWIRTZ, S.; MCLAUGHLIN E. (Ed.). New managerialism, new welfare? London: Sage, 2000.

PACHECO, J. A. Políticas curriculares: a decisão (re)centralizada. In: COLÓQUIO DA AIPELF/AFIRSE, 7., 1998, Lisboa. Anais... Lisboa: Faculdade de Psicologia e Ciências da Educação, 1998. p. $42-45$.

SACHS, J. The activist teaching profession. Buckigham: Open Unversity Press, 2003.

SAMMONS, P. et al. Exploring variations in teachers' work, lives and their effects on pupils: key findings and implications from a longitudinal mixed-method study. British Educational Research Journal, Londres/ Inglaterra, v. 33, n. 5, p. 681-701, 2007.

STRATHERN, M. 'The tyranny of transparency'. British Educational Research Journal, Londres/Inglaterra, v. 26, n. 3, p. 309-321, 2000.

SUGRUE, C. A Critical Appraisal of the impact of international agencies on educational reforms and teachers' lives and work: the case of Ireland? European Educational Research Journal, Londres/Inglaterra, v. 5, n. 3/4, p. 181-195, 2006.

SUGRUE, C. Profissionalismo e performatividade: a experiência dos professores irlandeses no tango entre a política e a prática. In: FLORES, M. A. (Ed.). A avaliação de professores numa perspectiva internacional: sentidos e implicaçóes. Porto: Areal, 2010. p. 163-196.

SUGRUE, C. Rhetorics and realities of CPD across Europe: from cacophony towards coherence. In: DAY, C.; SACHS, J. (Ed.). International Handbook on the Continuing Professional Development of Teachers. Maidenhead: Open University, 2004.

TORRES, J. A desmotivaçāo dos professores. Mangualde: Pedago, 2006. WHITTY, G. Teacher Professionalism in New Times. Journal of InService Education, v. 26, n. 2, p. 281-295, 2000. 


\section{Trends and tensions in the work of teachers: reflections on the voices of teachers}

\section{Abstract}

This paper reflects on the work of teachers' by drawing upon the voices of teachers who participated in a broad study conducted in Portugal. Based upon their perspectives and existing literature on the topic, the paper explores a number of dimensions of and trends in teachers' work, namely increased bureaucracy, intensification, and control; the "pressure to perform" and accountability, and the increased surveillance and public scrutiny of schools and teachers' work. The paper is based on an ongoing study into the effects of recent policies, namely those relating to teacher performance appraisal and the status of the teaching career, on teachers' work. Data was collected at two Portuguese schools. The paper concludes with reflections on the effects of recent trends on the ways teachers experience their profession, especially concerning their motivation to remain in teaching or to leave the profession, and also considers the emotional dimension.

Keywords: Teacher's work. Professionalism. Professional Identity.

\section{Tendéncias y tensiones en el trabajo docente: reflexiones a partir de la voz de los profesores}

\section{Resumen}

En este artículo presentamos un conjunto de reflexiones acerca del trabajo docente a partir de las voces de los profesores que participaron en un estudio más largo en Portugal. Partiendo de testigos de varios docentes y reuniendo la literatura existente en este dominio, analizamos un conjunto de dimensiones y de tendencias del trabajo docente, nombradamente, la creciente burocracia, la intensificación y el control sobre el trabajo de los profesores; la agenda de prestación de cuentas y del performativo y a cada vez una vigilancia más grande y un escrutinio público en relación al trabajo de las escuelas y de los profesores. Este texto se basa en datos de una investigación en curso que busca analizar los efectos de las recientes medidas políticas, nombradamente relativas a la evaluación del rendimiento y al estatuto de la carrera docente, en el trabajo de los profesores a partir de datos recogidos en dos escuelas portuguesas. El texto termina con algunas reflexiones sobre los efectos de las recientes tendencias en el modo de estar y de vivir la profesión docente, especialmente en lo que concierne la motivación para permanecer o abandonar la enseńanza y a su dimensión afectiva y emocional.

Palabras clave: Trabajo docente. Profesionalismo. Identidad Profesional. 
Maria Assunçáo Flores

E-mail: aflores@ie.uminho.pt

Recebido em: 17/3/2011

Versáo final recebida em: $8 / 5 / 2011$

Aprovado em: 5/4/2011 